\title{
IN MEMORIAM: ROBERTO ARENDAR
}

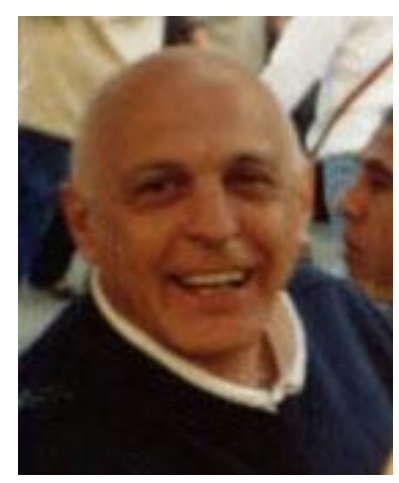

\section{Realizado por Raúl Naranjo Valentín ${ }^{1}$}

En ocasiones, ante acontecimientos que parecen inexorables, se despiertan en nosotros esperanzas de que lo imposible tenga lugar y que nuestros deseos se impongan a la cruda realidad. Finalmente, ésta, ocupa el lugar que le corresponde y nos deja el pesar y la aceptación de nuestra condición mortal. Durante los últimos tiempos, los que nos manteníamos en contacto con Roberto Arendar, escuchábamos con ilusión y esperanza las noticias de la buena evolución de su grave estado de salud, acompañados del ímpetu y la energía vital que solían acompañarle. Sin embargo, el pasado 28 de Septiembre, nos trajo la triste noticia de su fallecimiento en Buenos Aires, tras un rápido empeoramiento de su enfermedad.

La pérdida de Roberto nos deja sin un amigo y sin un autor que desde el otro lado del atlántico resonaba nuestros mismos pensamientos e inquietudes, con su estilo propio, apasionado y entusiasta, a la vez que muy descriptivo y clarificador.

Su trayectoria profesional, según el propio Arendar describió en la Conferencia IARPP de Santiago de Chile en 2013, estuvo dividida en 3 etapas diferenciadas.

La primera etapa fue la de su formación como médico residente en psiquiatría en el hospital psiquiátrico José T. Borda de Buenos Aires. En esta etapa entra en contacto con la realidad de la patología mental, la clínica psiquiátrica, la psicofarmacología, etc. Es

\footnotetext{
${ }_{1}^{1}$ Naranjo Valentín, R. (2019). In Memoriam: Roberto Arendar. Clínica e Investigación Relacional, 13 (2): 537-542. [ISSN 1988-2939] [Recuperado de www.ceir.info ] DOI: 10.21110/19882939.2019.130216
} 
también aquí cuando a través de la influencia de algunos psiquiatras, comienza a conocer sobre la psiquiatría dinámica, el valor de la subjetividad del paciente y de las experiencias reales en la conformación de la psicopatología. Comienza a entrar en contacto con Searles, Fairbairn, Frieda Fromm-Reichmann o la escuela de Palo Alto. Todo ello le orienta hacia la necesidad de formarse en el ámbito del psicoanálisis.

La segunda etapa es precisamente la relacionada con su trayectoria formativa y de pertenencia a las instituciones psicoanalíticas. Arendar inició esta formación en 1979 en la Asociación Psicoanalítica de Buenos Aires (ApdeBa), institución de reciente creación y que había nacido de una escisión de la Asociación Psicoanalítica Argentina (APA). A lo largo de su trayectoria formativa, encontró elementos de admiración y disfrute en la obra de Freud (su prosa, su erudición, la búsqueda de un sentido a los síntomas...) pero también empezó a vislumbrar elementos que no le satisfacian de los planteamientos del psicoanálisis clásico, como la visión negativa del narcisismo o los planteamientos kleinianos que mostraban al ser humano poseído por impulsos destructivos. Pese a esta progresiva desafección con los enfoques más ortodoxos, otros profesores le mostraron e introdujeron a autores que posteriormente le influirían enormemente. Asi Guillermo Lancelle le hizo conocer la obra de Kohut y Alfredo Painceira la de Winnicott. Pero también comenzó a interesarse enormemente por la Teoria del Apego de Bowlby, las obras de Howard Bacal, Robert Stolorow, etc. A mediados de los go comienza a escribir y presentar sus trabajos, vinculados a estos autores y enfoques y según describe el propio Arendar encuentra muy poca receptividad en su entorno institucional, cuando no un claro y evidente rechazo a tales planteamientos. En 2001, abandona APdeBA por lo que describe como un desaire de un compañero de la institución, y que siente como la gota que colma el vaso de su insatisfacción en la misma.

La última etapa, arranca desde su necesidad de encontrar a otros colegas que sintiesen esta necesidad de cuestionar los modelos clásicos del psicoanálisis. Arendar destaca especialmente la lectura del texto de Ramon Riera "Transformaciones en mi práctica psicoanalítica. Un trayecto personal con el soporte de la teoría intersubjetiva y de la psicología del Self" publicado en 2001. Esta lectura, el posterior contacto con Ramon Riera y Rosa Velasco y su visita a Barcelona significó, en palabras del propio Arendar un antes y un después en su vida personal y profesional. Fue sobre todo un encuentro especular con personas con quien sentía que compartía similares puntos de vista del trabajo terapéutico y también una inyección de reconocimiento y validación profesional. A través de esta nueva conexión fue tomando contacto con el pensamiento de Mitchell y la corriente relacional y fue estableciendo una vinculación más profunda con los colegas de España; con visitas periódicas a Madrid y publicaciones en esta revista. Arendar señala que para 
que él pudiese dar continuidad a estas tareas fue fundamental la perseverancia y entusiasmo de Alejandro Avila, al que también expresó especial agradecimiento. Los que le conocíamos personalmente sabíamos lo importante y trascendental que para Arendar eran estos encuentros y visitas a España y la sensación de conexión con todas nosotros.

Gran parte de su pensamiento estaba centrado en resignificar algunos de los "pecados capitales" según el psicoanálisis clásico: la agresión, la culpa, la envidia, el narcisismo, que recibían una nueva mirada, señalando los aspectos patológicos, pero también los sanos que estaban presentes en estas dimensiones y sobre todo su carácter reactivo y adaptativo a entornos desfavorables e hirientes para el sujeto.

Cobraban especial interés las temáticas relacionadas con la autoestima y la construcción de un sentimiento de valía. Arendar nos hablaba de todos los elementos que era necesario que se aportasen al sujeto en su desarrollo para la construcción de este sentimiento de valía y al mismo tiempo, ponía el énfasis en los contextos intersubjetivos que afectaban gravemente al mismo, y generaban convicciones invalidares que dificultaban cualquier intento de alimentar la autoestima del sujeto. En esta área, me parece que las aportaciones de Arendar fueron especialmente interesantes y ricas, y muy cercanas a nuestra experiencia clínica con los pacientes.

Por otro lado, varios de sus escritos se centraban en el aferramiento a figuras y vínculos patológicos, y la dificultad del terapeuta para lograr el cambio, con la consiguiente sensación de frustración y desesperanza. Arendar nos mostraba aquí la importancia de sostener la dialéctica entre la aceptación y el cambio, el difícil equilibrio entre comprender las complejas necesidades de vinculación a lo patológico, con el deseo, también presente de cambio y de transformación.

En cuanto a la técnica del trabajo terapéutico, mostraba un especial interés en el valor fundamental de la empatía y la comprensión genuina del paciente. Se mostraba favorable al uso abierto y flexible de la técnica, sin los corsés del análisis clásico: renuncia al uso del diván, a la neutralidad, considera muy positivo el uso adecuado y medido de la auto revelación, etc. Además, aportó el interesante uso de los contenidos de la literatura y la cultura popular, tales como cuentos, películas, etc. para facilitar la comprensión de los problemas del paciente.

Pero Roberto no fue solo un autor al que leí con interés y me aporto muchas e interesantes ideas, fue sobre todo una persona a la que conocí en lo personal en mi estancia en Buenos Aires en 2007. Ejerció de magnífico anfitrión y me ofreció la oportunidad de conocer a su mujer y sus hijos con los que establecí un gran afecto. Nuestras interacciones versaban por supuesto sobre asuntos de nuestra profesión, pero también sobre cuestiones sociales, expresa. Este material es para uso científico y profesional exclusivamente y puede contener información clínica sensible. Los editores no se responsabilizan de los contenidos de los autores. Dirigir las consultas sobre derechos y autorizaciones a ceir@psicoterapiarelacional.es 
sobre su interés por viajar a Europa y en muchos casos nos conectábamos a través de grandes dosis de humor compartido. Tras mi estancia en Buenos Aires, mantuvimos una fluida comunicación por e-mail en la que me solía enviar sus trabajos con verdadero interés en mis aportaciones. Leerle y escribirle siempre me resultó muy fácil y natural, jamas me sentí constreñido a comentarle lo que me sugerían sus palabras. Imagino que esto tenia que ver con el clima de cercanía y confianza que era capaz de generar. Supongo que también influía el hecho de que compartíamos en gran medida nuestras visiones e intereses sobre el trabajo terapéutico.

Recuerdo especialmente compartir algunos el interés en algunos films que nos habían impresionado y que nos conectaban con los fenómenos que ocurrían en la vida de los pacientes y en el propio trabajo terapéutico. También nuestro interés común en la obra de Paul L Wachtel, al que yo había conocido a través de una entrevista y con el que Roberto pudo ponerse en contacto.

Y de entre todas las cosas, quizá me quede con lo que en una ocasión me comentó en una de nuestras comunicaciones. Me indicó que debería escribir más, porque lo hacía bien y porque mis reflexiones eran profundas y valiosas, que le aportaban mucho. Por supuesto, además de alimentar mi narcisismo y mi necesidad de sentirme valioso, me hizo pensar en que algo de mis capacidades quizá se estaba quedando estancado y no le estaba dando el espacio necesario en mi vida. Creo que este es un ejemplo de una intervención en cierta medida terapéutica, que aun resuena en mí, y que quizá hable de la habilidad de Roberto Arendar para hacer mella en el otro desde un simple comentario. Así que este pequeño homenaje escrito, es también un tributo a ese consejo, Roberto, y espero que mis palabras puedan aportarle algo a tu memoria.

\section{Trabajos de Roberto Arendar, publicados en CeIR \\ La autoestima y sus vicisitudes (otra vuelta de tuerca). Roberto Arendar}

Este trabajo amplía uno anterior de 2014. Apoyado en tres ilustraciones clínicas el autor concluye que: 1) los trastornos de la autoestima son ubicuos; 2) hemos de prestar atención a las convicciones irracionales de defectuosidad e inferioridad que las sustentan; 3) hemos de explorar los distintos contextos intersubjetivos pasados y presentes que han contribuido a forjar la baja autoestima; 4) las configuraciones relacionales que sustentan esa baja autoestima tienen carácter recurrente y 5) el avance en la autoestima es discontinuo, se avanza y se retrocede, y es la tendencia a su mejora lo que ha de importarnos. 


\section{La autoestima y sus vicisitudes. Roberto Arendar.}

Exploro en este trabajo las vicisitudes de la autoestima en el campo del trabajo clínico. Usando un lenguaje lo más evocativo posible me ocupo de subrayar los indicios que dan cuenta de un trastorno en esta área, los contextos intersubjetivos más frecuentes que tienden a forjar estos déficits y las estrategias psicoterapéuticas más eficaces para ayudar a los pacientes a subsanarlos. En relación con este último punto señalo los errores más usuales que se tienden a cometer y sus desafortunadas consecuencias. Ofrezco algunos ejemplos clínicos.

\section{Más vale malo conocido que bueno por conocer (Roberto Arendar).}

En este trabajo continúo desarrollando un tema que abordé anteriormente en "¿Hundirse con el Titanic?, a saber, el tenaz aferramiento que solemos encontrar en nuestros pacientes a relaciones o situaciones insatisfactorias. Hago hincapié en el peso decisivo que tiene en la conformación de este hecho de comprobación clínica la cuestión de la familiaridad. También exploro, valiéndome de tres películas, la actitud mental más adecuada a lograr para promover cambios favorables en estos sistemas que tienden a perpetuarse. Explico las razones de peso que sustentan lo necesario de tal actitud. Asimismo, me refiero a algunos recursos personales a los que podemos echar mano para incrementar nuestra eficacia terapéutica.

\section{La esperanza y el trauma (Roberto Arendar).}

Cuando Alejandro Ávila me solicitó una colaboración para el ciclo de conferencias sobre trauma que viene desarrollando la Institución dicho pedido produjo resultados insospechados. Por un lado, cuando pensé en la paciente acerca de la cual podría escribir surgió en mi cabeza mi paciente María Laura, aquella de la cual hablo en mis trabajos sobre vergüenza, con su historia de haber padecido abusos y violencia físicas y morales. Curiosamente, esa paciente, había interrumpido su terapia, para mi gran pesar, a principios de 2009. Ese hecho desafortunado fue uno de los factores que contribuyó al trabajo sobre el "Titanic".

\section{¿Hundirse con el Titanic? (Roberto Arendar).}

La idea que dio lugar a este trabajo se gestó una noche en la que mi mujer, ya acostada en la cama, estaba viendo muy entretenida por televisión una de esas películas en blanco y negro, de los años 40 ó 50, que tanto nos gustan a ambos. La película en cuestión era "Titanic" del año 1953, protagonizada por Clifton Webb y Barbara Stanwyck. Por lo tanto, yo también ya acostado, me dispuse a acompañarla a verla. Al principio debo reconocer que me pareció un poco melodramática y estuve a punto de dedicarme a hacer otra cosa, cuando de pronto hubo algo en la trama argumental del film que capturó mi atención...

\section{Un buen trabajo (Roberto Arendar y Hilda Cerrota).}

Un buen trabajo psicoanalítico, cuando uno lo reconoce, produce un impacto estético en nuestra experiencia subjetiva similar al que uno tiene cuando está en presencia de una 
obra de arte. ¿Cuáles habían sido los factores que habían contribuido a esa impresión? ¿Qué era lo que me llevaba a sentir y pensar que estaba en presencia de un trabajo bello, bien hecho, efectivo? ¿Cuáles son los ingredientes que, hoy en día, definen un buen trabajo psicoanalítico? Para desarrollar estos temas mostraré en primer lugar el relato de una colega, luego la serie de reflexiones y observaciones a que dio lugar en un grupo y finalmente a los procesos evolutivos que este ejercicio permitió detectar.

\section{Entrevista con Roberto Arendar (Raúl Naranjo Valentín).}

Raúl Naranjo: Roberto, tus intereses en los últimos tiempos han estado centrados en diferentes aspectos. Por ejemplo, en reflejar cómo nos experimentan los pacientes a los terapeutas, poniendo el relato precisamente en la voz de estos pacientes... ¿Cómo surgió este interés?

Roberto Arendar: Bueno pues a través del contacto clínico con mis pacientes y del relato que me hacían de sus experiencias terapéuticas anteriores, de pronto empecé a encontrar ciertos lugares comunes que se repetían y que habían tenido un efecto de ahuyentarlos de los consultorios o de hacerlos decepcionar del poder terapéutico de la experiencia que estaban iniciando. Esos eran pacientes que podían haber sido tranquilamente muy beneficiados en su momento por un tratamiento llevado a cabo bajo criterios más saludables y adecuados que otros.

\section{Pistas para una búsqueda de psicoterapeuta (Roberto Arendar).}

Inspira este artículo la preocupación del autor por ciertas circunstancias que conspiran o han conspirado contra la eficacia de la psicoterapia y, por lo tanto, contra la posibilidad de que las personas necesitadas de ayuda psicológica reciban una respuesta satisfactoria a dicha necesidad y que, por sobre todo, no los decepcione $y$, en consecuencia, corra el riesgo de abortar o truncar la posibilidad de beneficiarse de su potencial curativo. Intenta para ello poner de manifiesto muchos de los mitos o supuestos irracionales que persisten enquistados en la práctica psicoanalítica, que tienen mucho que ver con esos malos resultados. Se utiliza el relato de dos pacientes para ilustrar de manera gráfica y elocuente el accionar deletéreo de dichos supuestos.

\section{El trabajo terapéutico de la verguenza (Roberto Arendar).}

Se explora el papel de las convicciones invalidantes en el afecto de vergüenza y las dificultades que producen en la vida del paciente. La modificación de tales convicciones, fuertemente establecidas en nuestra psique, se presenta desde diferentes estrategias clínicas: A través de metáforas, versiones alternativas de los cuentos y de las fábulas, películas o las propias experiencias personales del analista. Mediante esta exploración se aborda el tema de la naturaleza de la acción terapéutica y de los cambios que en los últimos tiempos se han ido produciendo dentro del psicoanálisis en esta área, y se ilustra mediante un caso clínico. 